\title{
OPTIMASI PELAKSANAAN PENERTIBAN PEMAKAIAN TENAGA LISTRIK (P2TL) SEBAGAI UPAYA PENINGKATAN SAVING KWH DAN PENEKANAN SUSUT NON TEKNIS DI PT. PLN (PERSERO) RAYON SEMARANG SELATAN
}

\author{
Irene Ega Novena Putri, Arkhan Subari \\ Program Studi Diploma III Teknik Elektro \\ Fakultas Teknik Universitas Diponegoro
}

\begin{abstract}
Irene Ega Novena Putri, Arkhan Subari, in this paper explain that this study will describe the existing condition P2TL implementation in Rayon South Semarang, examine the root of the problem of lack of optimal implementation of P2TL, and describes efforts to optimizing the implementation in Rayon P2TL South Semarang. The method used is a combination of quantitative and qualitative. The approach used to establish the conditions of implementation P2TL is through observation by setting a good standard P2TL, examining implementation procedures and examined the results of the implementation P2TL P2TL in January-March and discussed the obstacles in its implementation. The approach used to discuss in detail P2TL performance in January-March was through discussion violations committed customers, the amount of saving $k W h$ for three months, the effect of saving $\mathrm{kWh}$ in the percentage of shrinkage, and effort optimizing the performance of P2TL.

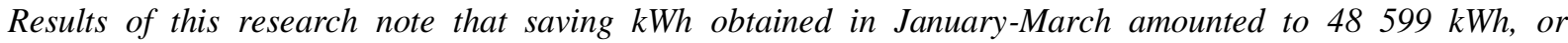
approximately $13 \%$ of the targeted savings through the implementation P2TL $k W h$, thus concluded that the performance P2TL not optimal. Effect of $k W h$ saved is able to suppress shrinkage in January by $0.16 \%$ and in March by $0.5 \%$. Efforts should be made in order to optimize the implementation of technically P2TL is through Early Detection of Violations. Efforts should be made in order to optimize the implementation of the non technical P2TL is through targeting of saving $\mathrm{kWh}$ monthly, fixing TO Rayon, a sweeping legalization customers, regeneration P2TL implementation team, and socialization prepaid electricity.
\end{abstract}

Keywords: P2TL, shrinkage, saving kWh, TO.

\section{PENDAHULUAN}

Listrik adalah komponen terpenting dalam kehidupan manusia modern, hampir semua aktivitas manusia membutuhkan listrik sehingga tidak dapat dipungkiri bahwa listrik merupakan nyawa bagi kehidupan manusia saat ini. Berdasarkan kewajiban konsumen yang selanjutnya akan disebut dengan pelanggan, pelanggan diwajibkan salah satunya untuk memanfaatkan tenaga listrik sesuai dengan peruntukannya. Pada kenyataannya masih ada pelanggan yang melakukan pelanggaran pemakaian tenaga listrik, oleh karenanya pelaksanaan Penertiban Pemakaian Tenaga Listrik sangatlah diperlukan. Hal tersebut dibarengi dengan fakta yang ada dimana inovasi Listrik Prabayar yang dilengkapi dengan meter yang dapat mencegah upaya pelanggaran, baru bisa mengcover $12 \%$ pelanggan dari total 62.660 pelanggan Rayon Semarang Selatan pada bulan Februari 2013.

Pelaksanaan Penertiban Pemakaian Tenaga Listrik yang baik diharapkan dapat meningkatkan jumlah saving kWh dan menekan susut non teknis dalam sistem distribusi. Berdasarkan Action Plan Penekanan Susut 2013, kegiatan P2TL mampu menyumbang saving kWh yang cukup besar apabila dikerjakan dengan baik. Nilai saving $\mathrm{kWh}$ dari pelaksanaan P2TL merupakan yang terbesar dari 44 jenis pekerjaan lainnya yaitu sebesar $371.641 \mathrm{kWh}$ dari total target saving $\mathrm{kWh}$ sebesar 1.344.486 kWh. Beranjak dari pemikiran tersebut maka penulis menganggap bahwa pengoptimasian pelaksanaan P2TL sangatlah penting untuk semakin meningkatkan kinerja P2TL yang saat ini sudah baik untuk semakin lebih baik lagi. Hal terpenting yang menjadi titik tumpu pemikiran penulis adalah mencari cara meningkatkan kinerja P2TL melalui penelitian akar masalahnya baik melalui cara teknis maupun cara non teknis. Pendekatan pertama yang dilakukan penulis adalah melalui penjelasan hasil pengamatan pelaksanaan P2TL di Rayon Semarang Selatan. Kedua adalah pembahasan jumlah dan bentuk pelanggaran serta pengaruhnya pada pengukuran meter, pembahasan perhitungan saving $\mathrm{kWh}$, pembahasan pengaruh saving $\mathrm{kWh}$ dalam menurunkan susut, dan penelitian akar masalah beserta upaya penangannya.

\section{LANDASAN TEORI}

Kata optimasi berasal dari kata kerja optimize dari kata sifat (adj) optimal. Bentukan kata optimal dengan imbuhan -ize akan membuat al pada optimal dipenggal sehingga hasilnya adalah optimize. Optimal adalah berusaha untuk memaksimumkan sesuatu yang diinginkan. Sedangkan Optimasi adalah cara untuk memaksimalkan atau mengoptimalkan sesuatu hal yang bertujuan untuk mengelola sesuatu yang dikerjakan.

Berdasarkan Kepdir PT. PLN(Persero) No: 1486.K/DIR/2011 Penertiban Pemakaian Tenaga Listrik adalah rangkaian kegiatan yang meliputi perencanaan (Tahap Pra P2TL), pemeriksaan, 
tindakan (Tahap Pelaksanaan P2TL) dan penyelesaian (Tahap Pasca P2TL) yang berupa penerbitan Surat Panggilan dan pemberian Tagihan Susulan. Untuk Pelanggaran Golongan 1 (P1) dikenakan denda berupa TS1 yang termasuk dalam pelanggaran ini adalah perubahan batasan daya dan perusakan segel. Untuk Pelanggaran Golongan 2 (P2) dikenakan denda berupa TS2 yang termasuk pelanggaran jenis ini adalah apabila pelanggan melakukan perubahan batasan daya dan perusakan segel milik PLN. Untuk pelanggaran Golongan 3 dikenakan TS3 yang termasuk dalam pelanggaran ini adalah apabila pelanggan melakukan Pelanggaran Golongan 1 dan 3. Untuk Pelanggaran Golongan 4 dikenakan TS4 pelanggaran ini dilakukan oleh non pelanggan (H. Aryawan, I Wayan. 2011). Perhitungan Tagihan susulan untuk setiap golongan tarif sama yang berbeda hanyalah harga listrik per kWh nya. Perhitungan saving $k W h$ hanya didapatkan dari Pelanggaran Golongan 2 dengan cara menghitung Tagihan Susulan 2.

$$
\begin{aligned}
& \text { TS } 2(R p) \\
& =9 \times 720 \text { jam } x \text { Daya Tersambung } \times 0,85 \\
& x \text { harga per } k W h
\end{aligned}
$$

Setelah didapatkan TS 2 maka perhitungan saving $k W h$ sebagai berikut.

$$
\text { Saving } k W h(k W h)=\frac{T S 2}{T D L \text { sesuai gol tarif }}
$$

Susut (losses) yang berdasarkan KepMenKeu nomor 431/KMK.06/2002: Bentuk kehilangan energi listrik yang berasal dari selisih sejumlah energi listrik yang dibeli dengan sejumlah energi listrik yang terjual atau jumlah energi yang hilang atau menyusut, terjadi karena sebab-sebab teknik maupun non teknik pada waktu penyediaan dan penyaluran energi. Rumus Perhitungan susut energi adalah

Susut $(\%)=$ $\frac{k W h \text { siap jual }-k W h \text { terjual (TUL III-09) }}{k W h \text { siap jual }} \times 100 \%$

Susut Non Teknis adalah susut yang tidak disebabkan oleh sifat alamiah material peralatan listrik. Root Cause Problem Solving (RCPS) Susut Non Teknis Area Semarang, adalah metode yang digunakan untuk melihat akar masalah penyebab susut non teknis. Berdasarkan RCPS Susut Non Teknis disebutkan bahwa P2TL yang tidak optimal disebabkan oleh DLPD, P2TL pelanggan legalisasi, dan penetapan TO P2TL, namun dalam hal ini penulis juga menambahkan hambatan-hambatan hasil wawancara dengan petugas pelaksana P2TL Rayon Semarang Selatan.

P2TL ditujukan salah satunya untuk menertibkan Sambungan Rumah (SR) dan APP (Alat Ukur Pembatas) yang ditujukan untuk mengurangi susut pada SR dan APP. Batasan milik
PLN dan batasan milik pelanggan pada Sambungan Listrik Tegangan Rendah ditunjukan oleh Gambar 1.

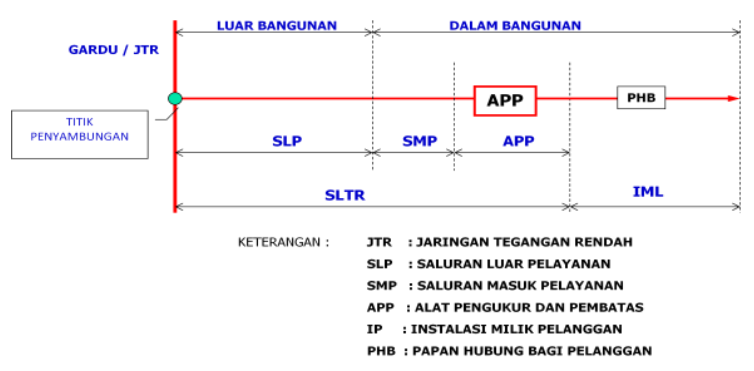

Gambar 1. Batasan Milik PLN dan Pelanggan

Pengukuran adalah untuk menentukan pemakaian daya dan energi listrik, dalam pengukuran ini alat yang digunakan meliputi meter $\mathrm{kWh}$, meter kVArh, meter kVA maksimum, meter arus dan meter tegangan (Sarimun, 2011:142). Pengukuran beban pada kWh meter adalah Beban 1 Fasa (kWh)

$=V$ fase $x I \times \operatorname{Cos} \varphi x$ pemakaianBeban 3 Fasa $(k W h)$ $=\sqrt{3} x V_{p-p} x \operatorname{I} x \operatorname{Cos} \varphi x$ pemakaian

Sedangkan perhitungan daya untuk 1 phasa adalah $\begin{array}{ll}\text { Daya Semu } & : \mathrm{S}=\mathrm{V} \times \mathrm{I}(\mathrm{VA}) \\ \text { Daya Nyata } & : \mathrm{P}=\mathrm{V} \times \mathrm{I} \times \cos \varphi(\text { watt) } \\ \text { Daya Reaktif } & : \mathrm{Q}=\mathrm{V} \times \mathrm{I} \times \sin \varphi(\mathrm{VAR})\end{array}$

Sedangkan perhitungan daya untuk sistem 3 phasa adalah

Daya Semu $: S=V \times I x \sqrt{3}(\mathrm{VA})$

Daya Nyata $\quad: \mathrm{P}=\mathrm{V} \times \mathrm{I} \times \sqrt{3} \times \cos \theta$ (Watt)

Daya Reaktif $\quad: Q=V \times I \times \sqrt{ } 3 \times \sin \theta(\mathrm{VAR})$

Sumber Tiga Fase memiliki tiga terminal yang disebut terminal jalur, dan sumber tersebut mungkin memiliki terminal keempat yaitu hubungan netral. William H. Hayt (Hayt, 2005:398) menjelaskan bahwa sumber tiga fasa seimbang dengan tegangan ideal yang terhubung dalam suatu $\mathrm{Y}$, didefinisikan memiliki

dan

$$
\left[V_{r n}\right]=\left[\mathrm{V}_{\mathrm{sn}}\right]=\left[\mathrm{V}_{\mathrm{tn}}\right]
$$

$$
V_{r n}+V_{s n}+V_{t n}=0
$$

Ketiga tegangan ini, masing-masingnya berada di satu jalur dan netral disebut tegangan fase. Jika dipilih sebarang $V_{r n}$ sebagai rujukan atau mendefinisikan

$$
V_{r n}=V_{p}<0^{\circ}
$$

Dimana kita secara konsisten memakai $V_{p}$ untuk mempresentasikan amplitudo rms dari sembarang tegangan fase, maka definisi dari sebarang sumber 3 fase menandakan bahwa

$V_{s n}=V_{p}<-120^{\circ}$ dan $V_{t n}=V_{p}<-240^{\circ}$ atau

$V_{s n}=V_{p}<120^{\circ}$ dan $\quad V_{t n}=V_{p}<240^{\circ}$ 
Baris yang pertama disebut urutan fasa positif atau urutan fasa rst sedangkan baris kedua disebut urutan fasa negatif atau urutan fasa tsr dan urutan fasa rst digambarkan dengan diagram fasor seperti pada Gambar 2. Urutan fasa yang aktual dari sumber tiga fasa tergantung dari pilihan sebarang dari ketiga terminal yang ditandai $r$, s, dan t. Ketiganya selalu dipilih agar menjadi urutan positif dan diasumsikan bahwa sistem ini yang dipakai dari sebagian besar sistem yang akan dibahas.

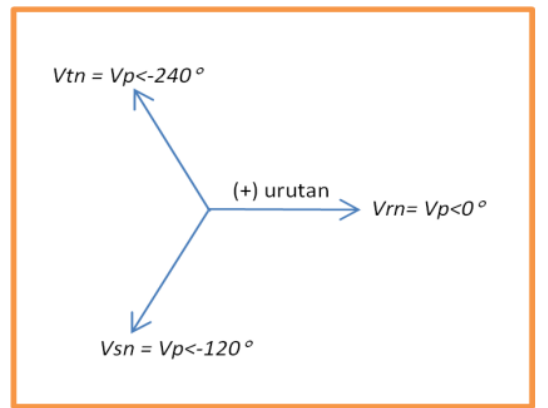

Gambar 2. Urutan fasa positif atau rst

Penentuan tegangan jalur ke jalur yang sering disebut dengan tegangan jalur yang ada saat tegangan fase seperti pada Gambar 2. Tegangan ini paling mudah dicari dengan menggunakan diagram fasor, karena sudut-sudutnya semua dalam kelipatan $30^{\circ}$. Konstruksi yang diperlukan diperlihatkan pada Gambar 3. hasilnya adalah $V_{r s}=\sqrt{3} V_{p}<30^{\circ}$

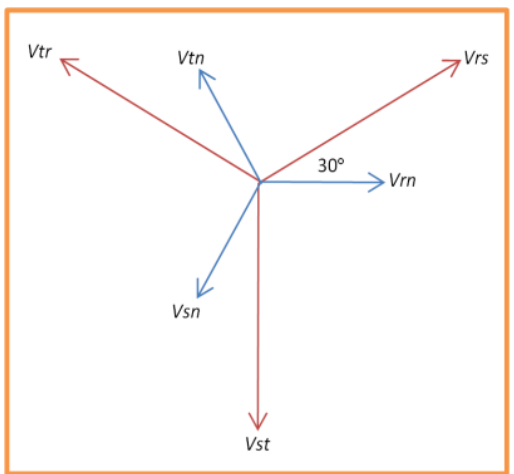

Gambar 3. Diagram Fasor untuk Menentukan Tegangan Jalur dari Teg Fase

$V_{s t}=\sqrt{3} V_{p}<-90^{\circ}$

$V_{t r}=\sqrt{3} V_{p}<-210^{\circ}$

Jika ampitudo rms dari sebarang tegangan jalur dilambangkan dengan $V_{L}$ maka salah satu karakteristik yang penting dari sumber tiga fase yang terhubung $\mathrm{Y}$ diekspresikan sebagai

$$
V_{L}=\sqrt{3} V_{P}
$$

Apabila beban tiga fase terhubung $\mathrm{Y}$ seimbang dengan sumber, memakai tiga jalur dan satu netral. Beban tersebut direpresentasikan oleh impedansi Zp di antara setiap jalur dan netral. Ketiga arus jalur ditentukan dengan mudah seperti berikut

$$
\begin{gathered}
I_{r R}=\frac{V_{r n}}{Z_{p}} \\
I_{s S}=\frac{V_{s n}}{Z_{p}}=\frac{V_{r n}<-120^{\circ}}{Z_{p}}=I_{r R}<-120 \\
I_{t T}=I_{r R}<-240^{\circ}
\end{gathered}
$$

maka netral tidak membawa arus jika sumber dan beban sama-sama seimbang dan keempat kawat memiliki impedansi nol.

$$
I_{N n}=I_{a A}+I_{b B}+I_{c C}=0
$$

Daya yang diserap oleh setiap fase $\mathrm{R}$ adalah

$$
P_{R}=V_{p} \cdot I_{r R} \cdot \cos \left(\operatorname{ang} V_{r n}-a n g I_{r R}\right)
$$

sehingga daya pada kedua fase yang lain adalah

$$
\begin{aligned}
& P_{S}=V_{p} \cdot I_{s S} \cdot \cos \left(a n g V_{s n}-a n g I_{s S}\right) \\
& P_{T}=V_{p} \cdot I_{t T} \cdot \cos \left(\operatorname{ang} V_{t n}-a n g I_{t T}\right)
\end{aligned}
$$

Pembatasan adalah batas pemakaian daya, sesuai daya tersambung yang menggunakan alat pembatas yang meliputi untuk sambungan TR menggunakan MCB dan untuk sambungan TM menggunakan OLR. Persamaan untuk menentukan pembatas adalah seperti pada persamaan di bawah ini.

Daya 1 Fasa

Daya 3 Fasa

$$
I(\text { Ampere })=\frac{S}{V}
$$

$$
I(\text { Ampere })=\frac{S}{\sqrt{3} x V_{p h-p h}}
$$

\section{METODOLOGI PENELITIAN}

Metode penelitian adalah suatu prosedur atau cara untuk mengetahui sesuatu yang mempunyai langkah-langkah sistematis (Usman, 2008: 41). Metode yang digunakan dalam penelitian ini adalah metode penelitian gabungan antara metodekualitatif dan kuantitatif.Metode kuantitatif menggunakan data existing yang diperlukan dengan cara mengolah lagi data tersebut agar mudah dipahami. Model kualitatif, metodenya menggunakan riset partisipatori, instrumen pengambilan datanya berupa panduan wawancara. Metode ini dilakukan agar hasil analisis data pada metode kuantitatif dapat di deskripsikan lebih jelas dengan metode kualitatif. Bahan pengamatan yang dipakai adalah

- Laporan pendapatan P2TL per golongan tarif Rayon Semarang Selatan

- Penetapan Tagihan Susulan (Tunai dan Angsuran) Rayon Semarang Selatan

- Data A1-CR Laporan Pelaksanaan P2TL Rayon Semarang Selatan

- Data TUL III-09 Rayon Semarang Selatan 
- Data Listrik Pra Bayar belum beli token 3 bulan Rayon Semarang Selatan

- Data Listrik Pra Bayar belum beli token 5 bulan Rayon Semarang Selatan

- Data jumlah pelanggan legalisasi Rayon Semarang Selatan

- Data prosentase susut 3 bulan target dan realisasi Rayon Semarang Selatan

- Data target susut Area Semarang 2013

- Data DLPD KWh max Rayon Semarang Selatan

- Data hasil wawancara dengan petugas pelaksana P2TL Rayon Semarang Selatan.

Alat pengumpul data yang digunakan adalah kamera, alat perekam suara, dan laptop. Jalan pengamatan tugas akhir adalah melalui yang pertama pengumpulan data, teknik pengumpulan data yang digunakan adalah triangulasi. Langkah pengamatan yang kedua adalah pengolahan data, teknik pengolahan datanya adalah melalui mengorganisasi data, membuat kategori, dan sintesisasi laporan, serta menulis laporan.

\section{PEMBAHASAN}

\section{Hasil Pengamatan}

Standar pelaksanaan P2TL yang baik adalah apabila dapat memenuhi target saving $k W h$ pada tahun 2013 dan membantu penekanan susut agar mencapai angka 5,2\%. Berdasarkan Action Plan Penekanan Susut 2013 terdapat total 44 jenis pekerjaan untuk menekan susut secara teknis maupun non teknis, dengan distribusi 29 jenis pekerjaan untuk menekan susut teknis dan 15 pekerjaan untuk menekan susut non teknis. Pelaksanaan P2TL merupakan salah satu pekerjaan untuk menekan susut non teknis dengan target saving $\mathrm{kWh}$ sebesar $371.641 \mathrm{kWh}$ untuk tahun 2013. Apabila kegiatan P2TL berhasil dilaksanakan dengan target saving $\mathrm{kWh}$ sebesar $371.641 \mathrm{kWh}$, maka sudah mampu menyumbang lebih dari seperempat total target saving kWh tahun 2013. Lebih tepatnya kegiatan P2TL ini mampu menyumbang $27,64 \%$ dari total saving $\mathrm{kWh}$ yang sebesar 1.344.486 kWh, dan apabila dirunut dari 43 jenis pekerjaan untuk menekan susut yang lain pelaksanaan P2TL adalah pekerjaan yang menyumbang saving $\mathrm{kWh}$ terbesar.

Pelaksanaan P2TL di Rayon Semarang Selatan sudah sesuai prosedur. Hasil pelaksanaan P2TL ditunjukkan pada tabel 1.

Tabel 1. Hasil Pelaksanaan P2TL

\begin{tabular}{|c|c|c|c|c|c|}
\hline \multirow[t]{2}{*}{ Bulan } & \multirow{2}{*}{$\begin{array}{c}\text { Pemerik } \\
\text { saan }\end{array}$} & \multirow{2}{*}{$\begin{array}{l}\text { Pelang } \\
\text { garan }\end{array}$} & \multicolumn{3}{|c|}{$\begin{array}{c}\text { Jenis } \\
\text { Pelanggaran }\end{array}$} \\
\hline & & & P1 & $\mathbf{P 2}$ & P3 \\
\hline Januari & 183 & 5 & 2 & 2 & 1 \\
\hline Februari & 204 & 13 & 13 & 0 & 0 \\
\hline Maret & 605 & 8 & 6 & 1 & 1 \\
\hline
\end{tabular}

\section{Hasil Pelaksanaan \\ Pelanggaran Golongan 1}

Kasus Pelanggaran Golongan 1 dikarenakan pemasangan MCB Ilegal 6 A pada daya $900 \mathrm{VA}$. Berikut hasil perhitungan pembatas arus yang seharusnya terpasang pada daya $900 \mathrm{VA}$ dengan menggunakan persamaan (2.21)

$$
\begin{aligned}
I(\text { Ampere })=\frac{S}{V} & =\frac{900}{220}=4,09 \text { Ampere } \\
& \approx 4 \text { Ampere }
\end{aligned}
$$

Berdasarkan perhitungan tersebut maka seharusnya pembatas arus yang digunakan adalah MCB CL4 dengan arus pengenal 4 Ampere yang sesuai dengan standar yang ditetapkan oleh PT. PLN (Persero). Jadi apabila pelanggan ingin menggunakan pembatas arus dengan arus pengenal 6 Ampere secara legal, pelanggan seharusnya melakukan penambahan daya sebesar 1300 VA, secara perhitungan dengan menggunakan persamaan (2.21) dibuktikan sebagai berikut

$$
\begin{aligned}
& I(\text { Ampere })=\frac{S}{V} \\
& S=I x V=6 X 220=1320 \mathrm{VA} \approx 1300 \mathrm{VA}
\end{aligned}
$$

\section{Modus Pelanggaran pada kWh meter 3Phasa}

Selama bulan Januari sampai dengan Maret 2013 tidak terdapat pelanggaran pada pelanggan yang menggunakan meter 3 phasa. Namun, penulis akan sedikit membahas mengenai satu contoh pelanggaran pada pelanggan yang menggunakan jenis APP dengan $\mathrm{kWh}$ meter 3 phasa pengukuran langsung dengan cara membalik arus pada phasa $\mathrm{R}$ yang ditunjukan oleh wiring pada Gambar 4. Pada gambar tersebut terlihat bahwa arus fasa pada fasa $\mathrm{R}$ dibalik, seharusnya untuk wiring normal seperti pada fasa $S$ dan $T$.

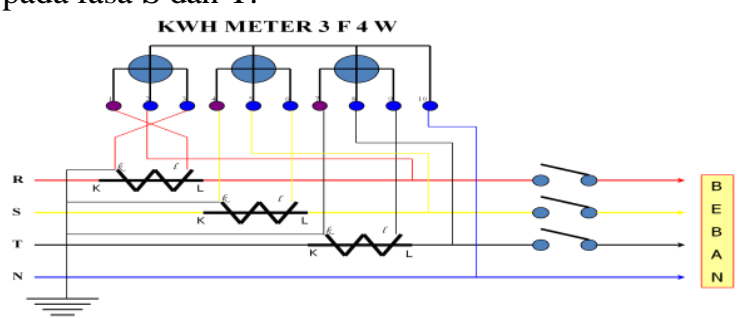

Gambar 4. Wiring modus Arus Fasa R terbalik

Sebelum menghitung $\mathrm{kWh}$ yang terukur pada posisi pelanggaran maka yang wajib dihitung pertama kali adalah pengukuran $\mathrm{kWh}$ saat dalam posisi normal. Diasumsikan sebuah sumber seimbang dan beban yang seimbang terhubung Y-Y empat-kawat-tiga-fase dengan rangkaian seperti pada Gambar 5. 


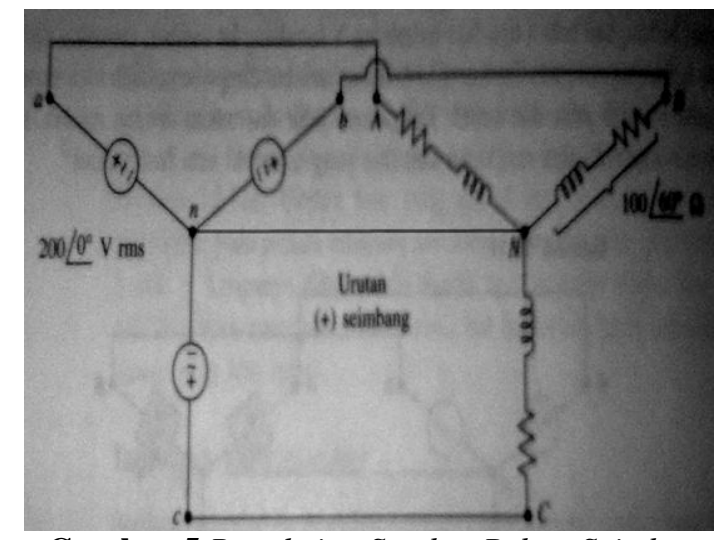

Gambar 5.Rangkaian Sumber Beban Seimbang Terhubung Y-Y 4 Kawat 3 Fasa

\section{Langkah 1}

Karena salah satu dari tegangan tiga fasa sumber telah diberikan maka digunakan urutan fasa positif, ketiga tegangan fasa adalah :

$V r n=200<0^{\circ} \mathrm{V}$

$V s n=200<-120^{\circ} \mathrm{V}$

$V t n=200<-240^{\circ} \mathrm{V}$

Sehingga tegangan jalur adalah :

$V_{L}=\sqrt{3} \cdot V_{P}=\sqrt{3} \cdot 200=346 \mathrm{~V}$

Dengan menggunakan persamaan (2.11) sampai (2.13)maka ditentukan tegangan jalur ke jalur adalah :

$$
\begin{aligned}
& V r s=\sqrt{3} \cdot V_{P}<30^{\circ}=\sqrt{3} \cdot 220<30^{\circ}=346 \\
& <30^{\circ} \mathrm{V} \\
& V s n=\sqrt{3} \cdot V_{P}<-90^{\circ}=\sqrt{3} \cdot 220<-90^{\circ}=346 \\
& <-90^{\circ} \mathrm{V} \\
& V s t=\sqrt{3} \cdot V_{P}<-210^{\circ}=\sqrt{3} \cdot 220<-210^{\circ} \\
& =346-210^{\circ} \mathrm{V}
\end{aligned}
$$

\section{Langkah 2}

Karena beban seimbang maka perhitungan arus pada setiap fasanya adalah seperti pada persamaan (2.14) sampai (2.16).

$$
I_{r R}=\frac{V_{r n}}{Z_{P}}=\frac{200<0^{\circ}}{100<60^{\circ}}=2<-60^{\circ} \mathrm{A}
$$

Apabila sistem seimbang maka akan sama dengan

$$
\begin{gathered}
I_{s S}=\frac{V_{s n}}{Z_{P}}=\frac{200<\left(-60^{\circ}-120^{\circ}\right)}{100<60^{\circ}}=2 \\
I_{t T}=\frac{V_{t n}}{Z_{P}}=\frac{200<\left(-180^{\circ} \mathrm{A}\right.}{<\left(-60^{\circ}-240^{\circ}\right)} \\
\begin{array}{c}
100<60^{\circ} \\
<-300^{\circ} \mathrm{A}
\end{array}
\end{gathered}
$$

Sistem tersebut seimbang dan dibuktikan sebagai berikut seperti pada persamaan (2.17) :

$$
\begin{aligned}
& I_{N}= I_{r R}+I_{s S}+I_{t T}=0 \\
& I_{N}=2<-60^{\circ}+2<-180^{\circ}+2<-300^{\circ} \\
&= 2\left(\cos -60^{\circ}+j \sin -60^{\circ}\right) \\
& \quad+2\left(\cos -180^{\circ}+j \sin -180^{\circ}\right) \\
& \quad+2\left(\cos -300+j \sin -300^{\circ}\right. \\
&=1-j 1,3-2+1+j 1,73=0+j 0=0<0^{\circ}
\end{aligned}
$$

\section{Langkah 3}

Gambar diagram fasor untuk pengawatan normal dimana arus pada fasa $\mathrm{R}$ belum dibalik seperti pada Gambar 6.

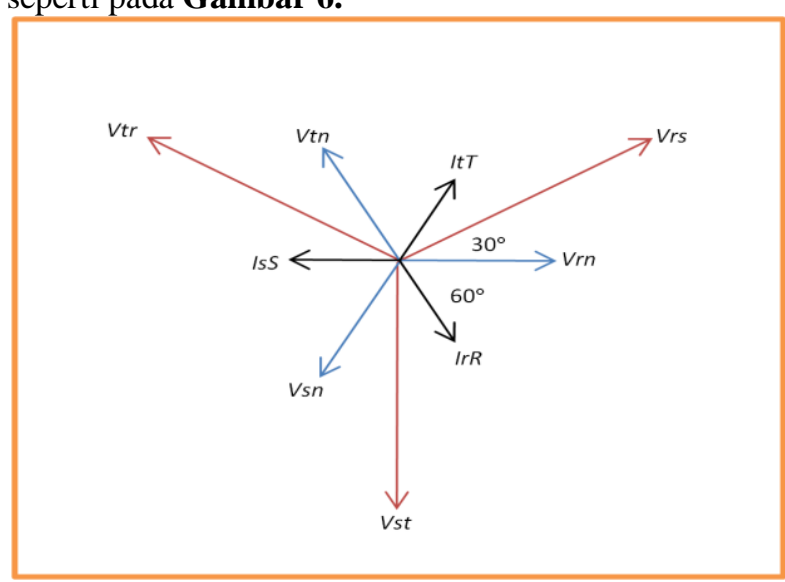

Gambar 6. Diagram Fasor Pengawatan Normal

\section{Langkah 4}

Daya yang ditunjukan oleh wattmeter 3 phasa adalah 600 watt, sebagai berikut

$$
\begin{array}{r}
P_{r}=V_{p} \cdot I_{r R} \cdot \operatorname{Cos}\left(\operatorname{ang} V_{r n}-\operatorname{ang} I_{r R}\right) \\
=200 \cdot 2 \cdot \cos \left(0^{\circ}+60^{\circ}\right)
\end{array}
$$$$
=200 \mathrm{watt}
$$

$P_{s}=V_{p} \cdot I_{s S} \cdot \operatorname{Cos}\left(\operatorname{ang} V_{s n}-\operatorname{ang} I_{s S}\right)$

$$
\begin{aligned}
& =200 \cdot 2 \cdot \cos \left(-120^{\circ}+180^{\circ}\right) \\
& =200 \mathrm{watt}
\end{aligned}
$$

$P_{t}=V_{p} \cdot I_{t T} \cdot \operatorname{Cos}\left(\operatorname{ang} V_{t n}-\operatorname{ang} I_{t T}\right)$

$$
\begin{aligned}
& =200 \cdot 2 \cdot \cos \left(-240^{\circ}+300^{\circ}\right) \\
& =200 \mathrm{watt}
\end{aligned}
$$

\section{Langkah 5}

Apabila arah arus pada fasa $\mathrm{R}$ dibalik maka diagram vektornya akan digambar ulang seperti yang ditunjukan pada Gambar 7.

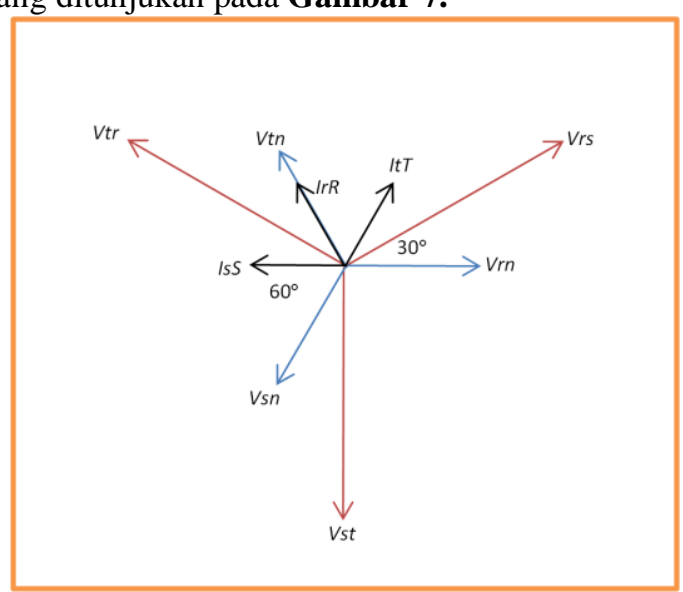

Gambar 7. Diagram Fasor pada Pengawatan Pembalikan Arah Arus Fasa R

\section{Langkah 6}

Apabila arah arus pada fasa $\mathrm{R}$ dibalik maka perubahan terjadi hanya pada fasa $\mathrm{R}$ saja sedangkan untuk fasa yang lain adalah tetap.

$$
I_{r R}=\frac{V_{r n}}{Z_{P}}=\frac{200<0^{\circ}}{100<60^{\circ}}=2<-60^{\circ} \mathrm{A}
$$


terbalik arah maka :

$$
I_{r R}=2<\left(-60^{\circ}-180^{\circ}\right)=2<-240^{\circ}
$$

Untuk fasa $\mathrm{S}$ dan $\mathrm{T}$ tetap seperti berikut :

$$
\begin{gathered}
I_{s S}=\frac{V_{s n}}{Z_{P}}=\frac{200<\left(-60^{\circ}-120^{\circ}\right)}{100<60^{\circ}}=2 \\
I_{t T}=\frac{V_{t n}}{Z_{P}}=\frac{200<\left(-180^{\circ} \mathrm{A}\right.}{<\left(-60^{\circ}-240^{\circ}\right)} \\
\begin{array}{c}
100<60^{\circ} \\
<-300^{\circ} \mathrm{A}
\end{array}
\end{gathered}
$$

\section{Langkah 7}

Daya yang ditunjukan oleh wattmeter 3 phasa dengan arah arus pada fasa $\mathrm{R}$ dibalik adalah :

$$
\begin{gathered}
P_{r}=V_{p} \cdot I_{r R} \cdot \operatorname{Cos}\left(\operatorname{ang} V_{r n}-\operatorname{ang} I_{r R}\right) \\
=200 \cdot 2 \cdot \cos \left(0^{\circ}+240^{\circ}\right) \\
=-200 \mathrm{watt} \\
P_{s}=V_{p} \cdot I_{s S} \cdot \operatorname{Cos}\left(\operatorname{ang} V_{s n}-\operatorname{ang} I_{s S}\right) \\
=200.2 \cdot \cos \left(-120^{\circ}+180^{\circ}\right) \\
=200 \mathrm{watt} \\
P_{t}=V_{p} \cdot I_{t T} \cdot \operatorname{Cos}\left(\operatorname{ang}_{t n}-\operatorname{ang} I_{t T}\right) \\
=200.2 \cdot \cos \left(-240^{\circ}+300^{\circ}\right) \\
=200 \mathrm{watt}
\end{gathered}
$$

Maka total daya yang diukur oleh wattmeter 3 phasa adalah :

$P_{\text {total }}=-200+200+200=200$ watt

Apabila dibandingkan dengan pengawatan normal maka daya yang terukur hanya $1 / 3$ dari pengawatan normal. Sehingga berdasarkan fakta tersebut maka modus ini cukup merugikan bagi PT. PLN (Persero) dan bila pelanggaran ini ditemukan oleh tim P2TL maka pelanggan yang melakukan pembalikan arah arus pada fasa $\mathrm{R}$ akan dikenakan P2 dengan denda berupa TS2. Berdasarkan gambar pengawatan terlihat bahwa jenis pengukuran yang digunakan adalah pengukuran langsung. Apabila dimisalkan pelanggan yang melakukan kecurangan adalah pelanggan golongan tarif R3 dengan daya 6.600 VA maka besar tagihan susulan dan saving $\mathrm{kWh}$ yang didapat adalah

$$
\begin{gathered}
\text { TS } 2=9 \times 720 \text { jam } \times\left(\frac{6.600 \mathrm{VA}}{1000}\right) \times 0,85 \\
\times \operatorname{Rp} 1.336,00 \text { per } \mathrm{kWh} \\
=9 \times 720 \times 6,6 \times 0,85 \times 1.336 \\
=\operatorname{Rp} 48.567 .340,00
\end{gathered}
$$

Saving kWh $=\left(\frac{R p 48.567 .340,00}{R p 1.336 / k W h}\right)=36.352 \mathrm{kWh}$

\section{Pengaruh Saving kWh pada Susut}

Tabel 2. Realisasi Pelanggaran P2 dan P3

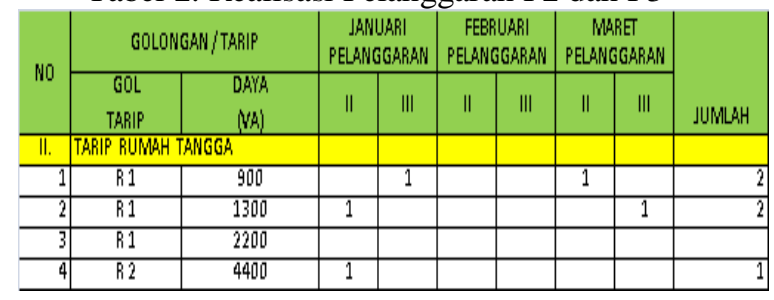

Untuk Golongan Tarif R1/900 terdapat 2 pelanggaran yaitu P2 dan P3. Perhitungan TS 2 pada keduanya sama jadi saving $\mathrm{kWh}$ yang didapat adalah sebagai berikut.

Jenis Pelanggaran P2 dan P3 (Perhitungan TS 2 saja)

TS $2=9$ × 720 jam $\times\left(\frac{900 \mathrm{VA}}{1000}\right) \times 0,85 \times \mathrm{Rp} 495,00$ per $\mathrm{kWh}$

$=9 \times 720 \times 0,9 \times 0,85 \times 49$

$=\operatorname{Rp} 2.453 .814,00$

Saving kWh $=\left(\frac{R p 2.453 .814,00}{R p 495 / k W h}\right)=4.957 \mathrm{kWh}$

Karena keduanya memiliki tarif yang sama maka perhitungan saving kWhnya adalah : savingkWh $=2 \times 4.957=9.914 k W h$

\section{RI/1300 VA}

Untuk Golongan Tarif R1/1300 terdapat 2 pelanggaran yaitu P2 dan P3. Perhitungan TS 2 pada keduanya sama jadi saving $\mathrm{kWh}$ yang didapat adalah sebagai berikut.

R1/1300 VA

Jenis pelanggaran P2 dan P3 (Perhitungan TS 2 saja)

TS $2=9 \times 720$ jam $\times\left(\frac{1300 \mathrm{VA}}{1000}\right) \times 0,85 \times \mathrm{Rp} 790,00$ per $\mathrm{kWh}$ $=9 \times 720 \times 1,3 \times 0,85 \times 790$

$=\operatorname{Rp} 5.656 .716,00$

Saving kWh $=\left(\frac{R p 5.656 .716,00}{R p 790 / k W h}\right)$

$$
=7.160 \mathrm{kWh}
$$

Karena keduanya memiliki tarif yang sama maka perhitungan saving kWhnya adalah : savingkWh $=2 \times 7.160=14.320 \mathrm{kWh}$

\section{$R 2 / 4400 V A$}

Jenis Pelanggaran P2

TS $2=9 \times 720$ jam $\times\left(\frac{4400 \mathrm{VA}}{1000}\right) \times 0,85 \times \mathrm{Rp} 890,00$ per $\mathrm{kWh}$ $=9 \times 720 \times 4,4 \times 0,85 \times 890=\operatorname{Rp} 21.569 .328,00$

Saving $\mathrm{kWh}=\left(\frac{R p 21.569 .328,00}{R p 890 / k W h}\right)=24.325 \mathrm{kWh}$

Sehingga dari perhitungan bulan Januari sampai dengan bulan Maret didapatkan jumah saving $\mathrm{kWh}$ sebesar $48.559 \mathrm{kWh}$ dengan penjabaran sebagai berikut.

Total SavingkWh

= saving $\mathrm{kWh}$ dari $\mathrm{R} 1 / 900 \mathrm{VA}+$ saving $\mathrm{kWh}$

$\mathrm{R} 1 / 1300 \mathrm{VA}+$ saving $\mathrm{kWh} \mathrm{R} 2 / 4400 \mathrm{VA}$

$=9.914 \mathrm{kWh}+14.320 \mathrm{kWh}+24.325 \mathrm{kWh}$

$=48.559 \mathrm{kWh}$

Pengaruh saving $\mathrm{kWh}$ pada susut bulan Januari adalah terlihat pada perbandingan perhitungan susut dengan saving $\mathrm{kWh}$ dan perhitungan susut tanpa saving $\mathrm{kWh}$ seperti berikut.

R1/900 VA 
Susut dengan memperhitungkan saving $\mathrm{kWh}$

Susut(\%)

$$
=\frac{k W h \text { siapjual }-k W h t e r j u a l(T U L I I I-09)}{k W h \text { siapjual }} \times 100 \%
$$$$
\text { Susut }(\%)=\frac{23.596 .844-21.051 .182}{23.596 .844} \times 100 \%
$$$$
=10,78 \%
$$

Susut tanpa memperhitungkan saving $\mathrm{kWh}$ kWhTerjualtanpasavingkWh

$$
\begin{gathered}
=21.051 .182-36.442 \\
=21.014 .740 \mathrm{kWh} \\
\text { Susut }(\%)=\frac{23.596 .844-21.014 .740}{23.596 .844} \times 100 \% \\
=10,94 \%
\end{gathered}
$$

Selisih dari susut tanpa dan dengan saving $\mathrm{kWh}$ adalah sebagai berikut.

$$
\begin{aligned}
\text { SelisihsusutJan } & =10,94 \%-10,78 \% \\
& =0,16 \%
\end{aligned}
$$

Pengaruh saving kWh pada susut bulan Februari adalah terlihat pada perbandingan perhitungan susut dengan saving $\mathrm{kWh}$ dan perhitungan susut tanpa saving $\mathrm{kWh}$ seperti berikut .

Susut dengan memperhitungkan saving $\mathrm{kWh}$ Susut (\%)

$$
\begin{gathered}
=\frac{k W h \text { siapjual }-k \text { Whterjual(TULIII }-09)}{k W h \text { siapjual }} \times 100 \% \\
\text { Susut }(\%)=\frac{22.113 .636-20.720 .355}{22.113 .636} \times 100 \% \\
=6,3 \%
\end{gathered}
$$

Susut tanpa memperhitungkan saving kWh kWhTerjualtanpasavingkWh

$$
\begin{aligned}
& =20.720 .355-0 \\
& =20.720 .355 \mathrm{kWh}
\end{aligned}
$$

Susut $(\%)=\frac{22.113 .636-20.720 .355}{22.113 .636} \times 100 \%$

$$
=6,3 \%
$$

Selisih dari susut tanpa dan dengan saving kWh adalah sebagai berikut.

Selisihsusut $=6,3 \%-6,3 \%=0 \%$

Pengaruh saving kWh pada susut bulan Maret adalah terlihat pada perbandingan perhitungan susut dengan saving $\mathrm{kWh}$ dan perhitungan susut tanpa saving $\mathrm{kWh}$ seperti berikut .

Susut dengan memperhitungkan saving $\mathrm{kWh}$ Susut (\%)

$$
\begin{gathered}
=\frac{k W h \text { siapjual }-k W h \text { terjual }(\text { TULIII }-09)}{k W h \text { siapjual }} \times 100 \% \\
\text { Susut }(\%)=\frac{25.499 .968-23.932 .676}{25.499 .968} \times 100 \% \\
=6,15 \%
\end{gathered}
$$

Susut tanpa memperhitungkan saving kWh kWhTerjualtanpasavingkWh

$$
\begin{gathered}
=23.932 .676-12.117 \\
=23.920 .559 \mathrm{kWh} \\
\operatorname{Susut}(\%)=\frac{25.499 .968-23.920 .559}{25.499 .968} \times 100 \% \\
=6,20 \%
\end{gathered}
$$

Selisih dari susut tanpa dan dengan saving kWh adalah sebagai berikut.

SelisihsusutFeb $=6,2 \%-6,15 \%=0,5 \%$

Berikut Grafik perbandingan dengan dan tanpa memperhitungkan saving kWh dari P2TL.

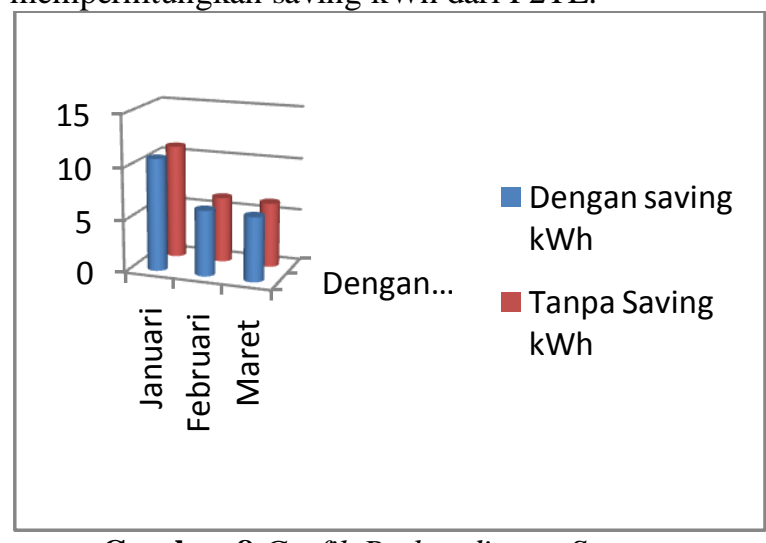

Gambar 8.Grafik Perbandingan Susut

\section{Penelitian Akar Masalah Teknis dan Non Teknis serta Upaya Penyelesaian}

Akar masalah penyebab belum optimalnya pelaksanaan P2TL secara teknis ini adalah belum adanya sistem deteksi awal melalui data teknis tentang adanya pelanggaran, karena sebenarnya hal ini juga dapat berguna dalam penentuan Target Operasi. Deteksi awal secara teknis ini masih belum ada, dikarenakan tidak adanya data pelanggan dalam satu trafo di Area Semarang dan tidak adanya meter pada trafo, sehingga susut energi tiap trafo dan kemungkinan adanya pelanggaran tidak dapat terlihat.

Langkah-langkah yang perlu dilakukan dalam Deteksi Awal Pelanggaran :

- Penentuan Daerah Sampling

Daerah sampling ini dipilih berdasarkan tingkat kepadatan jumlah pelanggan dan survei pelaku usaha terbanyak.

- Pendataan Pelanggan

Pendataan pelanggan dalam satu trafo, mencatat total pelanggan dan daya total yang terpasang sesuai SPJBTL.

- Pengukuran Arus pada Transformator Pelanggan

Pengukuran arus dilaksanakan saat WBP (Waktu Beban Puncak) yaitu pada pukul 17.00-22.00.

- Komparasi Data

Melakukan komparasi data apakah arus maksimal pada pemakaian pada beban puncak sesuai dengan arus maksimal yang seharusnya dipakai pelanggan berdasarkan data pelanggan. Apabila arus bocornya tinggi, maka hasil ini kemungkinan besar ada pelanggan yang melakukan pelanggaran. 
Sedangkan secara non teknis adalah sebagai berikut seperti pada Gambar 9.

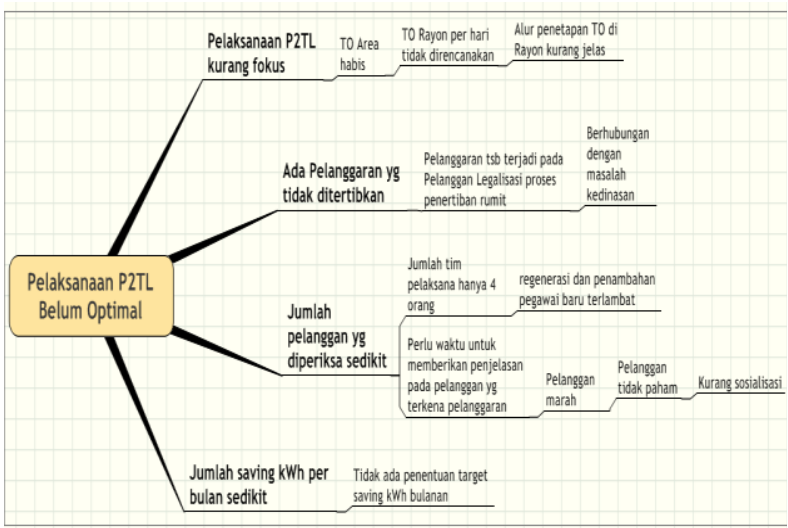

Gambar 9.RCPS Pelaksanaan P2TL Belum Optimal

- Penetapan TO Rayon dengan menilik data Daftar Langganan Perlu Diperhatikan (DLPD), Daftar Pembacaan Meter (DPM), Daftar Pemakaian kWh (DPK), dan dari sumber informan dengan memilah dan mengelompokkan data berdasarkan skala prioritasnya.

- Penertiban di lingkungan pelanggan Legalisasi.

- Regenerasi atau pengangkatan pegawai baru sangat dibutuhkan, untuk memberikan pelajaran bagi generasi muda. Hal ini dikarenakan hampir semua tim P2TL di 10 rayon yang ada di Area Semarang minim generasi muda dan sangat minim tenaga pelaksana, rata-rata per rayon hanya 2 orang saja.

- Sosialisasi Listrik Pra Bayar dan sosialisasi pemakaian tenaga listrik yang baik dan benar.

- Menentukan target saving kWh bulanan hal ini ditujukan untuk memenuhi target saving kWh tahunan. Selain itu, pengisian data yang sudah terealisasi juga diperlukan untuk mengetahui dan membandingkan apakah kinerja sudah sesuai dengan target yang ditentukan.

\section{KESIMPULAN}

- Berdasarkan data Action Plan Penekanan Susut 2013 Rayon Semarang Selatan, kegiatan P2TL menyumbang saving kWh sebesar $371.641 \mathrm{kWh}$ dari total target saving $\mathrm{kWh}$ sebesar 1.344.486 kWh.

- $\quad$ Saving kWh yang didapatkan selama Januari Maret sebesar $48.469 \mathrm{kWh}$ yang didapat dari 3 pelanggaran P2 dan 2 pelanggaran P3, maka masih ada sisa target sebesar $323.272 \mathrm{kWh}$

- Masalah pertama pelaksanaan Penertiban Pemakaian Tenaga Listrik (P2TL) yang kurang fokusternyata disebabkan oleh alur penetapan P2TL yang kurang jelas, cara penanganannya adalah dengan penerbitan Target Operasi Rayon oleh Manajer Rayon.

- Masalah kedua adalah ada pelanggaran yang tidak ditertibkan ternyata akar masalahnya adalah sulitnya menertibkan pelanggan legalisasi, cara penanganannya adalah dengan pendekatan dengan instansi bersangkutan.

- Masalah ketiga adalah jumlah pelanggan yang ditertibkan sedikit akar masalah penyebabnya ada dua yaitu jumlah tim pelaksana yang sedikit dan ketidakpahaman pelanggan, cara penanganannya adalah dengan melakukan regenerasi dan sosialisasi dengan pelanggan.

- Masalah keempat adalah tidak adanya target bulanan pada Action Plan Penekanan Susut sehingga pekerjaan pelaksanaan P2TL tidak optimal, cara penanganannya adalah dengan menetapkan target bulanan berdasarkan target tahunan dibagi 12 bulan.

\section{SARAN}

Pendataan pelanggan per trafo setiap rayon bagus untuk dilaksanakan terlebih bila di kemudian hari data tersebut dapat dimasukan dalam aplikasi AP2T. Selain itu demi menunjang pengukuran susut teknis pada jaringan dan susut pada transformator, mungkin perlu dipasang meter pada setiap transformator. Pendataan pelanggan per trafo dan pemasangan meter tiap trafo ini nantinya juga berguna dalam penentuan deteksi awal pelanggaran.

Pada proses pra P2TL sudah seharusnya penetapan TO Rayon menggunakan dataDaftar Langganan Perlu Diperhatikan (DLPD), Daftar Pembacaan Meter (DPM), Daftar Pemakaian kWh (DPK), dan dari sumber informan dengan memilah dan mengelompokkan data berdasarkan skala prioritasnya. Pada Proses pelaksanaan Penertiban Pemakaian Tenaga Listrik bisa semakin baik apabila ada regenerasi atau pengangkatan pegawai baru agar pekerjaan P2TL yang cukup banyak dapat tertangani dengan baik. Hal terpenting yang wajib diperhatikan untuk mengurangi pelanggaran adalah dengan melakukan sosialisasi Listrik Pra Bayar dan sosialisasi pemakaian tenaga listrik yang baik dan benar. Sehingga diharapkan masyarakat sadar akan pentingnya listrik bagi kehidupan dan kenyamanan menggunakkan Listrik Pra Bayar.

\section{DAFTAR PUSTAKA}

1. H. Aryawan, I Wayan. 2011. Penertiban Pemakaian Tenaga Listrik (P2TL). PT. PLN (Persero): Manado.

2. Hayt, William H; Kemmerly, Jack E; \& Durbin, M.Steven. 2005. Rangkaian Listrik: Edisi Keenam. Jakarta : Erlangga

3. Keputusan Direksi PT. PLN (Persero) Nomor: 1486.K/DIR/2011 yang sudah disahkan oleh 
keputusan Direktur Jendral Ketenagalistrikan Nomor: 33-12/23/600.

4. Keputusan Menteri Keuangan Republik Indonesia Nomor 431/KMK.06/2002 Tentang Tata Cara Penghitungan Dan Pembayaran Subsidi Listrik.
5. Sarimun, Wahyudi. 2011. Buku Saku Pelayanan Teknik (Yantek). Depok : Garamond. 